\title{
Role of Divalent Cations in Pathophysiology of Essential Hypertension
}

\author{
Asha $\mathbf{G}^{1}$, Jyothi A Natikar ${ }^{2}$, Shrabani Mohanty $^{3}$, Alapaty Shailaja ${ }^{4}$ \\ ${ }^{1,2}$ Assistant Professor, ${ }^{3,4}$ Professor \\ Department of Biochemistry, Vydehi Institute of Medical Sciences and Research Center, \\ Bangalore, Karnataka, India
}

Corresponding Author: Asha G

\begin{abstract}
Introduction: Essential hypertension (EHTN) accounts for $95 \%$ of all cases of hypertension affecting approximately one billion individuals worldwide. Alteration in trace elements like calcium and magnesium can be helpful in knowing the elemental involvement in the pathophysiology of EHTN and its associated complications.
\end{abstract}

\section{Aims and Objectives:}

1. To estimate serum levels of calcium and magnesium in patients of EHTN and compare it with normotensive healthy subjects.

2. To find the correlation of serum levels of calcium and magnesium with systolic blood pressure (SBP) and diastolic blood pressure (DBP) in patients of EHTN.

Materials and Methods: The study was conducted in 100 subjects, out of which 50 were essential hypertensive patients (cases) and 50 were normotensive healthy subjects (controls), within the age group of 25-65 years. Serum calcium and magnesium were measured by using the auto analyzer Beckman Coulter DXC 600. The results were analysed by using students ' $t$ ' test and Pearson's correlation.

Results: Our study found a significantly $\left(\mathrm{p}<0.001^{* *}\right)$ increased levels of serum calcium and significantly $\left(\mathrm{p}<0.001^{* *}\right)$ decreased levels of serum magnesium in cases as compared to controls. Our study also revealed a significant positive correlation between serum calcium with SBP $\left(r=0.842, \mathrm{p}<0.001^{* *}\right)$ and DBP $(\mathrm{r}=0.403$, $\left.\mathrm{p}=0.004^{* *}\right) ;$ and a significant negative correlation between serum magnesium with SBP $(\mathrm{r}=-0.805, \mathrm{p}<0.001 * *)$ and DBP $(\mathrm{r}=-0.395$, $\left.\mathrm{p}=0.005^{* *}\right)$ among essential hypertensives.
Keywords: EHTN-Essential hypertension, HTNHypertension, SBP-Systolic blood pressure, DBP-Diastolic blood pressure, BP-Blood pressure.

\section{INTRODUCTION}

Hypertension is a major risk factor for cardiac, cerebrovascular and renal diseases affecting, about 1 billion individuals worldwide have high blood pressure (BP), which is associated with approximately 7.1 million deaths per year.[1,2]

Treating HTN has been associated with about a $40 \%$ reduction in the risk of stroke and $15 \%$ reduction in the risk of myocardial infarction and associated morbidity and mortality. $[3,4]$

$2 \%$ to $5 \%$ of patients have underlying renal or adrenal diseases as the cause of raised BP called secondary hypertension. $95 \%$ to $98 \%$ of patients with no cause of raised $\mathrm{BP}$ and the condition is marked as primary or essential or idiopathic hypertension, affecting approximately 1 billion individuals worldwide.[5,6]

EHTN may be due to it's the consequence of an interaction between environmental and genetic factors. Prevalence of EHTN increases with age, and is at increased risk for the subsequent development of HTN.[7] Hypotheses proposed in the past about the mechanisms of EHTN are incompletely understood.[8]

The possible role of divalent cat ions in the pathogenesis of EHTN has received increasing attention. Studies done has 
shown the role of serum calcium and magnesium in pathophysiology of EHTN.[9]

Calcium plays an important role in the pathophysiology of EHTN. Increased calcium enhances vascular reactivity in hypertensives when compared with normotensives. Calcium has been shown to be positively correlated with increase in BP.[10]

Magnesium has gained importance as an essential cation, due to its depletion in cardiovascular pathophysiology.[11]

It alters vascular tone by altering endothelial function. Studies have shown an inverse correlation between BP and serum magnesium levels.[12]

The present study has been taken up to estimate the serum levels of calcium and magnesium, also to know its role as an elemental involvement in the pathophysiology of EHTN.

\section{Aims and Objectives}

1. To estimate serum levels of calcium and magnesium in patients with essential hypertension and compare it with normotensive healthy subjects.

2. To find the correlation of serum levels of calcium and magnesium with systolic blood pressure and diastolic blood pressure in patients with essential hypertension.

\section{MATERIALS AND METHODS}

The study was carried out for one year on confirmed essential hypertensive patients as cases visiting department of Medicine, at Vydehi Institute of Medical Sciences \& Research Centre, Bangalore; and age, sex matched normotensive healthy individuals as controls. Total 50 essential hypertensive cases and 50, age and sex matched apparently healthy controls were selected with age group between 25-65 years of which 25 males and 25 females.

An ethical clearance and an informed consent from the study subjects were duly obtained. Pregnant women, patients suffering from diseases of liver and kidney, diabetes mellitus, post myocardial infarction, congestive cardiac failure, hyperaldosteronism, Cushing's disease or pheochromocytoma, patients on diuretics, calcium channel blockers or angiotensin converting enzyme inhibitors were excluded from the study. Blood samples were collected and analysed for:

- Serum calcium-by ISE Electrolyte buffer reagent and ISE Electrolyte reference reagent kit method using Beckman Coulter SYNCHRON CX $^{\circledR}$ System DXC 600.

- Serum magnesium was measured by using Calmagite method using Beckman Coulter SYNCHRON $\mathrm{CX}^{\circledR} \quad$ System DXC 600.

\section{Statistical Analysis}

Student $t$ test (two tailed, independent) has been used to find the significance of study parameters on continuous scale between two groups (Inter group analysis) on metric parameters. Chisquare/ Fisher Exact test has been used to find the significance of study parameters on categorical scale between two or more groups. Pearson correlation between SBP/DBP with Serum calcium, Magnesium copper in cases and controls was performed. Significant figures

- + Suggestive significance $(\mathrm{P}$ value: $0.05<\mathrm{P}<0.10$ )

- * Moderately significant (P value: $0.01<\mathrm{P} \leq 0.05$ )

- ** Strongly significant $(\mathrm{P}$ value: $\mathrm{P} \leq 0.01)$

Statistical software: SPSS 15.0 was used for the analysis of the data and Microsoft word and Excel have been used to generate graphs, tables etc. [13,14,15]

\section{RESULTS}

Study Design: A Comparative case-control study with 50 controls and 50 cases is undertaken to study the levels of serum calcium, magnesium and copper. The cases and controls were age and sex matched. The age group was between 25-65 years. 
Table 1: Age distribution of patients in the study groups

\begin{tabular}{|c|c|c|c|c|}
\hline \multirow{2}{*}{ Age in years } & \multicolumn{2}{|c|}{ Cases } & \multicolumn{2}{c|}{ Controls } \\
\cline { 2 - 5 } & No & $\%$ & No & \% \\
\hline $25-30$ & 7 & 14.0 & 9 & 18.0 \\
\hline $31-40$ & 11 & 22.0 & 15 & 30.0 \\
\hline $41-50$ & 15 & 30.0 & 13 & 26.0 \\
\hline $51-60$ & 14 & 28.0 & 10 & 20.0 \\
\hline $61-65$ & 3 & 6.0 & 3 & 6.0 \\
\hline Total & $\mathbf{5 0}$ & $\mathbf{1 0 0 . 0}$ & $\mathbf{5 0}$ & $\mathbf{1 0 0 . 0}$ \\
\hline Mean \pm SD & $\mathbf{4 3 . 7 6} \pm \mathbf{1 1 . 7 2}$ & $\mathbf{3 9 . 2 8} \pm \mathbf{1 1 . 2 3}$ \\
\hline
\end{tabular}

As represented in the above table and figure, samples were matched according to their age. Maximum number of cases, $30 \%$ were in the age group of 41-50 yrs followed by $28 \%$ patients in $51-60$ yrs. The mean age in cases was $43.76 \pm 11.72 \mathrm{yrs}$ and in controls, it was $39.28 \pm 11.23$ yrs.

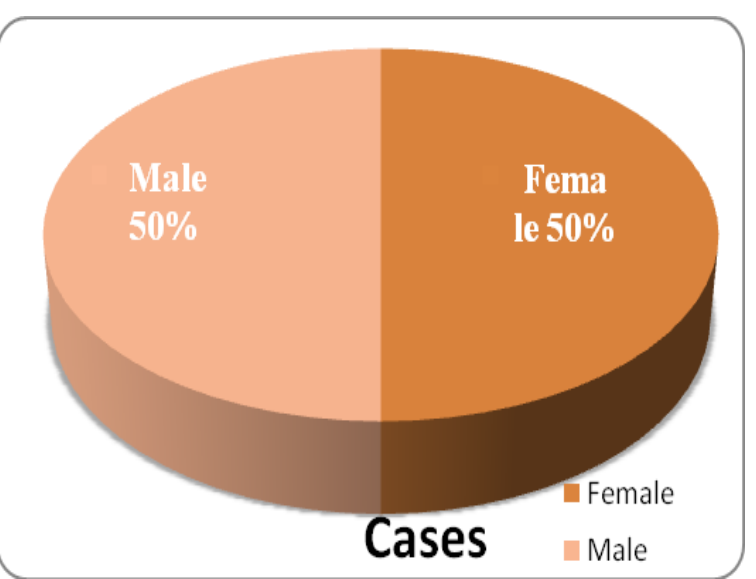

Fig 2: Pie chart showing the samples are gender matched

As represented in the above table and figure, among the cases, the number of males was 25 and females were 25 and controls number of males was 25 and females was 25. The cases and controls were sex matched with $\mathrm{p}=1.000$.

Table 3: SBP (mm Hg) in the study groups

\begin{tabular}{|c|c|c|c|c|}
\hline \multirow{2}{*}{$\begin{array}{c}\text { SBP } \\
(\mathbf{m m} \mathbf{H g})\end{array}$} & \multicolumn{2}{|c|}{ Cases } & \multicolumn{2}{c|}{ Controls } \\
\cline { 2 - 5 } & No & \% & No & $\%$ \\
\hline$<100$ & 0 & 0.0 & 0 & 0.0 \\
\hline $100-140$ & 0 & 0.0 & 50.0 & 100.0 \\
\hline$>140$ & 50 & 100.0 & 0 & 0.0 \\
\hline Total & $\mathbf{5 0}$ & $\mathbf{1 0 0 . 0}$ & $\mathbf{5 0}$ & $\mathbf{1 0 0 . 0}$ \\
\hline
\end{tabular}

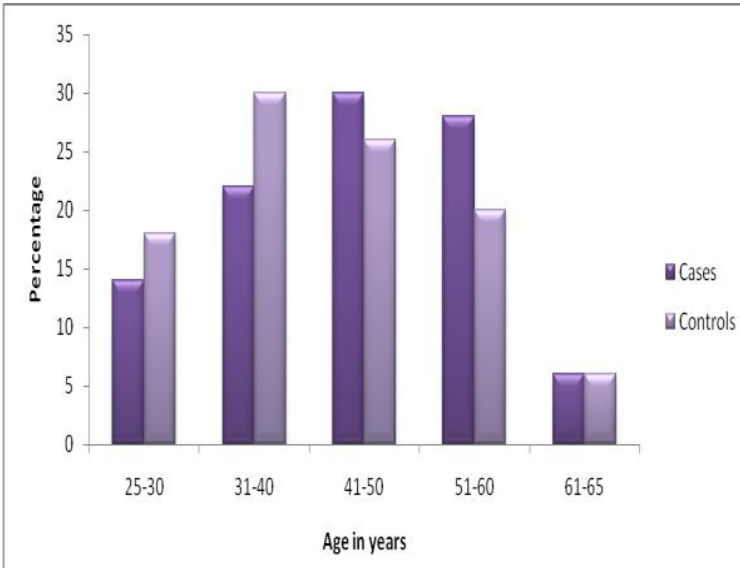

Fig 1: Bar diagram showing age distribution in the study groups

Table 2: Gender distribution in the study groups

\begin{tabular}{|c|c|c|c|c|}
\hline \multirow{2}{*}{ Gender } & \multicolumn{2}{|c|}{ Cases } & \multicolumn{2}{c|}{ Controls } \\
\cline { 2 - 5 } & No & \% & No & \% \\
\hline Female & 25 & 50.0 & 25 & 50.0 \\
\hline Male & 25 & 50.0 & 25 & 50.0 \\
\hline Total & $\mathbf{5 0}$ & $\mathbf{1 0 0 . 0}$ & $\mathbf{5 0}$ & $\mathbf{1 0 0 . 0}$ \\
\hline
\end{tabular}
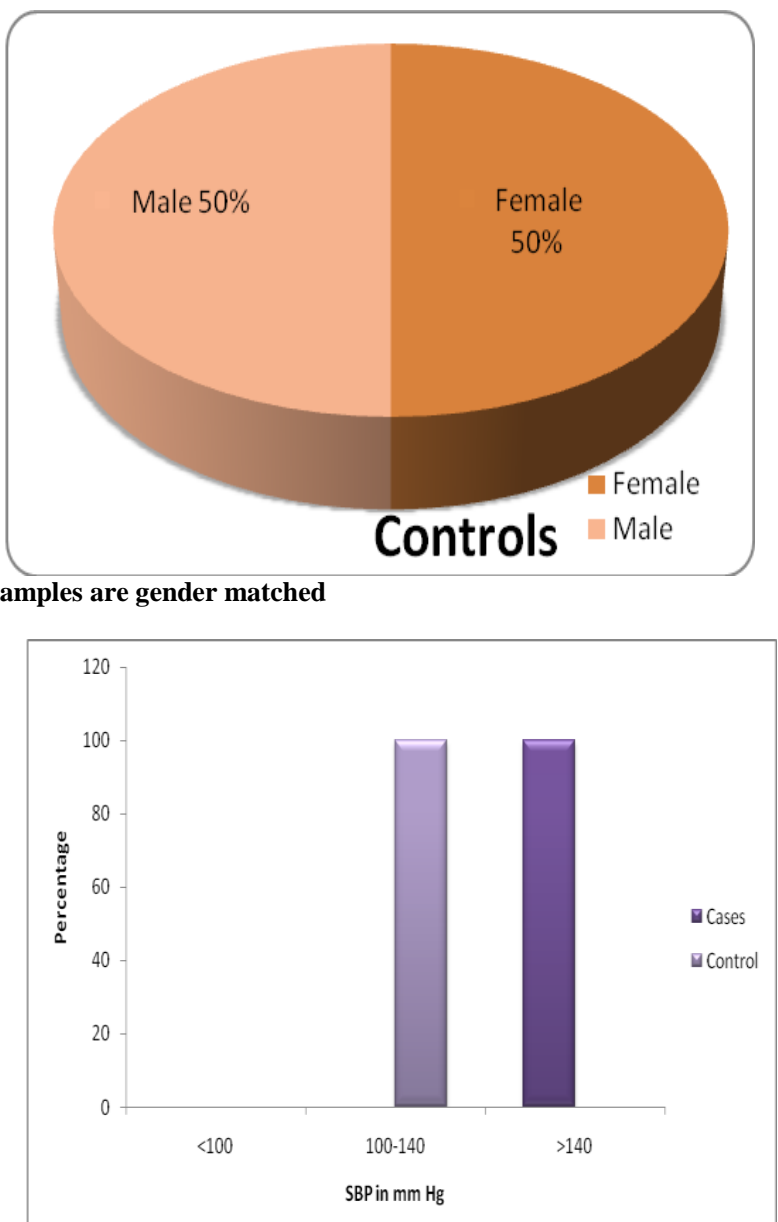

Fig 3: Bar diagram showing SBP in the study groups

As represented in the above table and figure, higher SBP is significantly more associated with cases than controls with $\mathrm{P}<0.001 * *$. 
Table 4: DBP (mm Hg) in the study groups

\begin{tabular}{|c|c|c|c|c|}
\hline \multirow{2}{*}{$\begin{array}{c}\text { DBP } \\
\mathbf{m m} \mathbf{H g})\end{array}$} & \multicolumn{2}{|c|}{ Cases } & \multicolumn{2}{c|}{ Controls } \\
\cline { 2 - 5 } & No & $\mathbf{\%}$ & No & \% \\
\hline$<70$ & 0 & 0.0 & 0 & 0.0 \\
\hline $70-90$ & 17 & 34.0 & 50 & 100.0 \\
\hline$>90$ & 33 & 66.0 & 0 & 0.0 \\
\hline Total & $\mathbf{5 0}$ & $\mathbf{1 0 0 . 0}$ & $\mathbf{5 0}$ & $\mathbf{1 0 0 . 0}$ \\
\hline
\end{tabular}

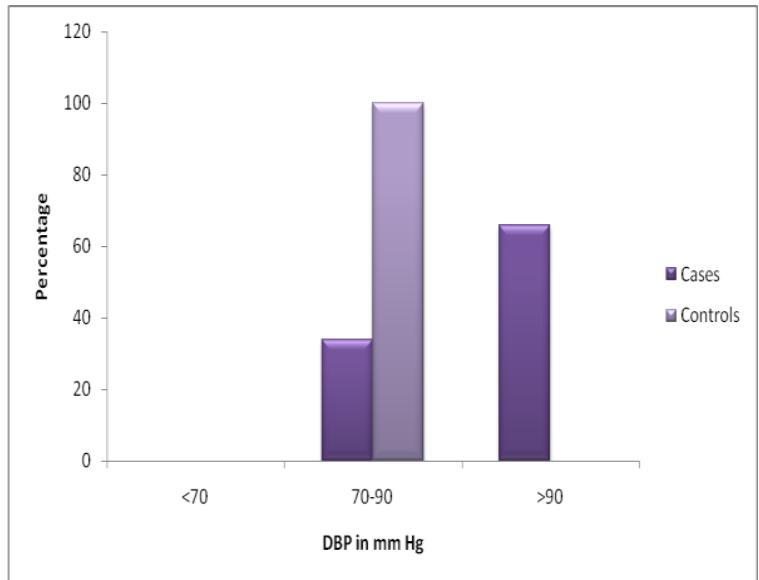

Fig 4: Bar diagram showing DBP in the study groups

As represented in the above table and figure, higher DBP is significantly more associated with cases than control with $\mathrm{P}<0.001 * *$.

\section{Distribution of serum calcium in the study groups}

Table 5: Serum calcium levels in the study groups
\begin{tabular}{|c|c|c|c|c|}
\hline $\begin{array}{c}\text { Calcium } \\
(\mathbf{m g} / \mathbf{d l})\end{array}$ & \multicolumn{2}{|c|}{ Cases } & \multicolumn{2}{c|}{ Controls } \\
\cline { 2 - 5 } & No & $\%$ & No & $\%$ \\
\hline$<8.5$ & 0 & 0.0 & 0 & 0.0 \\
\hline $8.5-10.2$ & 6 & 12.0 & 50 & 100.0 \\
\hline$>10.2$ & 54 & 54.0 & 0 & 0.0 \\
\hline Total & $\mathbf{5 0}$ & $\mathbf{1 0 0 . 0}$ & $\mathbf{5 0}$ & $\mathbf{1 0 0 . 0}$ \\
\hline
\end{tabular}

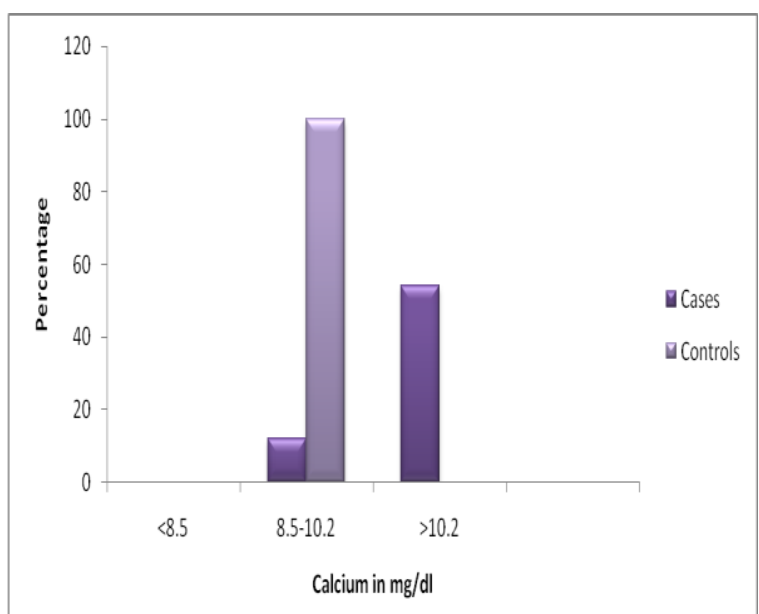

Fig 5: Bar diagram showing serum calcium levels in the study groups

As represented in the above table and figure, serum calcium levels were compared in both cases and controls. The normal level of serum calcium level is 8.5$10.2 \mathrm{mg} / \mathrm{dl}$. $54 \%$ cases had calcium levels above $10.2 \mathrm{mg} / \mathrm{dl}$; none of the controls had calcium levels above $10.2 \mathrm{mg} / \mathrm{dl} .12 \%$ of cases and $100 \%$ of controls had calcium levels between 8.5-10.2 mg/dl. Serum calcium levels are significantly more associated with cases with $\mathrm{p}<0.001 * *$.

\section{Distribution of serum magnesium in the study groups}

\begin{tabular}{|c|c|c|c|c|}
\hline Table 6: Serum magnesium levels in the study groups \\
\hline $\begin{array}{c}\text { Magnesium } \\
(\mathbf{m g} / \mathbf{d l})\end{array}$ & \multicolumn{2}{|c|}{ Cases } & \multicolumn{2}{c|}{ Controls } \\
\cline { 2 - 5 } & No & $\%$ & No & $\%$ \\
\hline$<1.7$ & 45 & 90.0 & 0 & 0.0 \\
\hline $1.7-2.8$ & 5 & 10.0 & 50 & 100.0 \\
\hline$>2.8$ & 0 & 0.0 & 0 & 0.0 \\
\hline Total & $\mathbf{5 0}$ & $\mathbf{1 0 0 . 0}$ & $\mathbf{5 0}$ & $\mathbf{1 0 0 . 0}$ \\
\hline
\end{tabular}

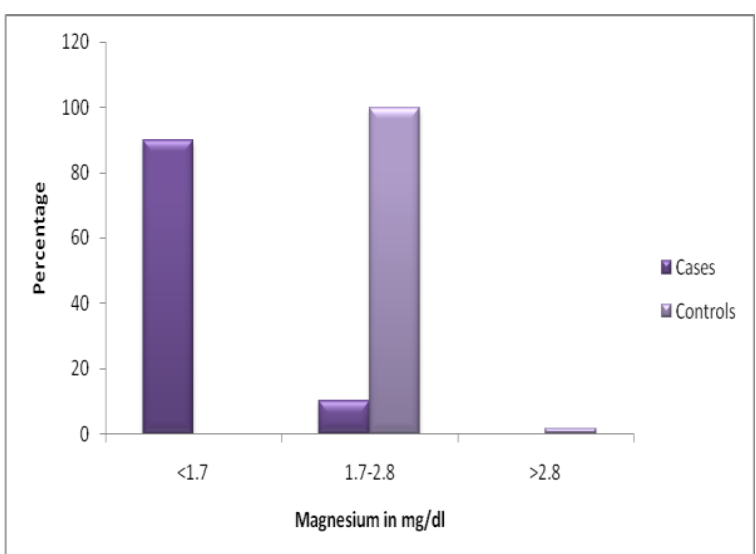

Fig 6: Bar diagram showing serum magnesium levels in the study groups

As represented in the above table and figure, serum magnesium levels were compared in both cases and controls. The normal level of serum magnesium level is $1.7-2.8 \mathrm{mg} / \mathrm{dl} .90 \%$ of cases had magnesium levels below $1.7 \mathrm{mg} / \mathrm{dl}$, none of the control levels had magnesium levels below 1.7 $\mathrm{mg} / \mathrm{dl} .10 \%$ of cases and $100 \%$ of controls had magnesium levels between 1.7-2.8 $\mathrm{mg} / \mathrm{dl}$.

Serum magnesium levels are significantly less associated with cases with $\mathrm{P}<0.001 * *$.

Table 7: Comparison of BP parameters in the study groups
\begin{tabular}{|c|c|c|c|}
\hline Parameters & Cases & Controls & P value \\
\hline SBP $(\mathrm{mm} \mathrm{Hg})$ & $163.76 \pm 12.04$ & $120.20 \pm 8.30$ & $<0.001^{* *}$ \\
\hline DBP $(\mathrm{mm} \mathrm{Hg})$ & $93.72 \pm 3.55$ & $74.48 \pm 5.02$ & $<0.001^{* *}$ \\
\hline
\end{tabular}



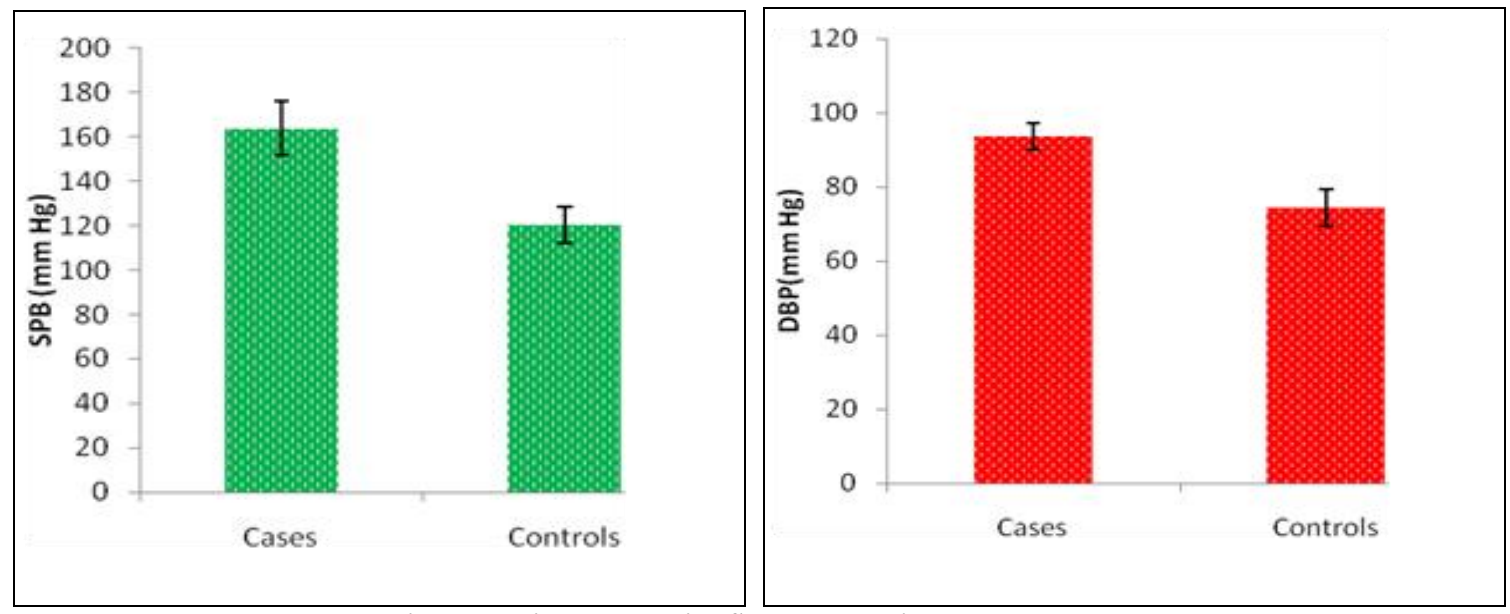

Fig 7: Bar diagram showing SBP and DBP in the study groups

As presented in the above table and figure, shows the mean SBP (mmHg) and DBP $(\mathrm{mmHg})$ in case and controls.

The mean values of SBP in cases are $163.76 \pm 12.04 \mathrm{mmHg}$ and controls is $120.20 \pm 8.30 \mathrm{mmHg}$. There is a statistically increase in SBP in cases as compared to controls, with $\mathrm{p}<0.001 * *$.

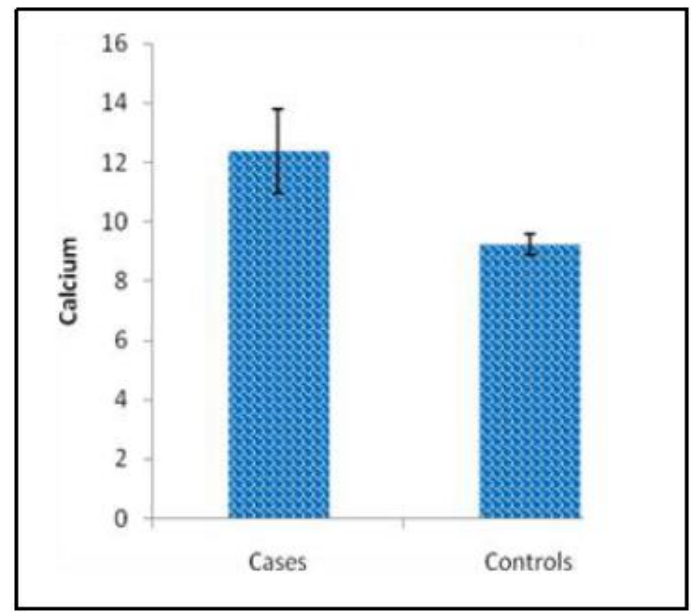

Fig 8: Bar diagram showing serum calcium and magnesium in the study groups
The mean values of DBP in cases are $93.72 \pm 3.55 \mathrm{mmHg}$ and controls is $74.48 \pm 5.02 \mathrm{mmHg}$. There is a statistically increase in DBP in cases as compared to controls, with $\mathrm{p}<0.001 * *$.

Table 8: Comparison of serum calcium, magnesium and copper in the study groups

\begin{tabular}{|c|c|c|c|}
\hline \multicolumn{1}{|c|}{ Parameters } & Cases & Controls & P value \\
\hline Calcium in $\mathrm{mg} / \mathrm{dl}$ & $12.38 \pm 1.42$ & $9.24 \pm 0.34$ & $<0.001^{* *}$ \\
\hline Magnesium in $\mathrm{mg} / \mathrm{dl}$ & $1.46 \pm 0.19$ & $1.98 \pm 0.15$ & $<0.001^{* *}$ \\
\hline
\end{tabular}

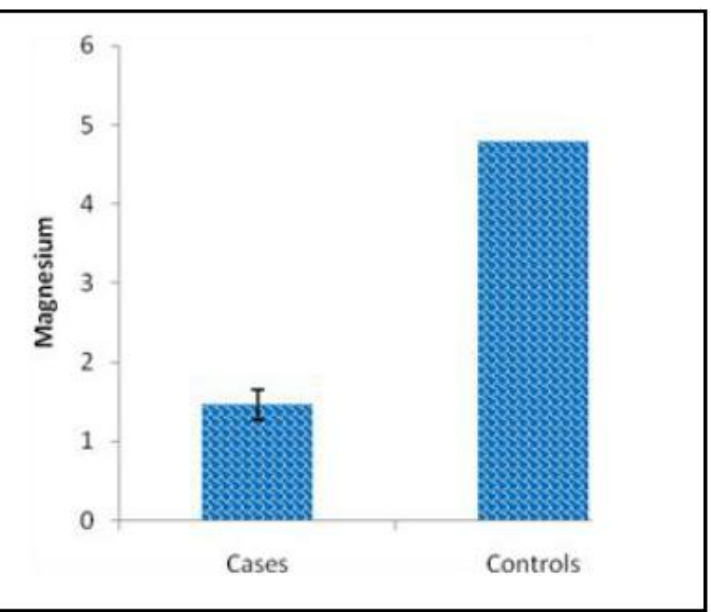

- Serum magnesium is significantly decreased in cases when compared to controls, with $\mathrm{p}<0.001^{* *}$.

Table 9: Pearson correlation of serum calcium, serum magnesium and serum copper with $\mathrm{BP}$ in the study groups

\begin{tabular}{|l|c|c|c|c|}
\hline \multirow{2}{*}{\multicolumn{1}{|c|}{ Pair }} & \multicolumn{2}{c|}{ Cases } & \multicolumn{2}{c|}{ Controls } \\
\cline { 2 - 5 } & r value & p value & r value & p value \\
\hline Calcium vs SBP & 0.842 & $<0.001^{* *}$ & 0.122 & 0.398 \\
\hline Magnesium vs SBP & -0.805 & $<0.001 * *$ & -0.002 & 0.991 \\
\hline Calcium vs DBP & 0.403 & $0.004 * *$ & -0.072 & 0.619 \\
\hline Magnesium vs DBP & -0.395 & $0.005 * *$ & -0.016 & 0.914 \\
\hline
\end{tabular}



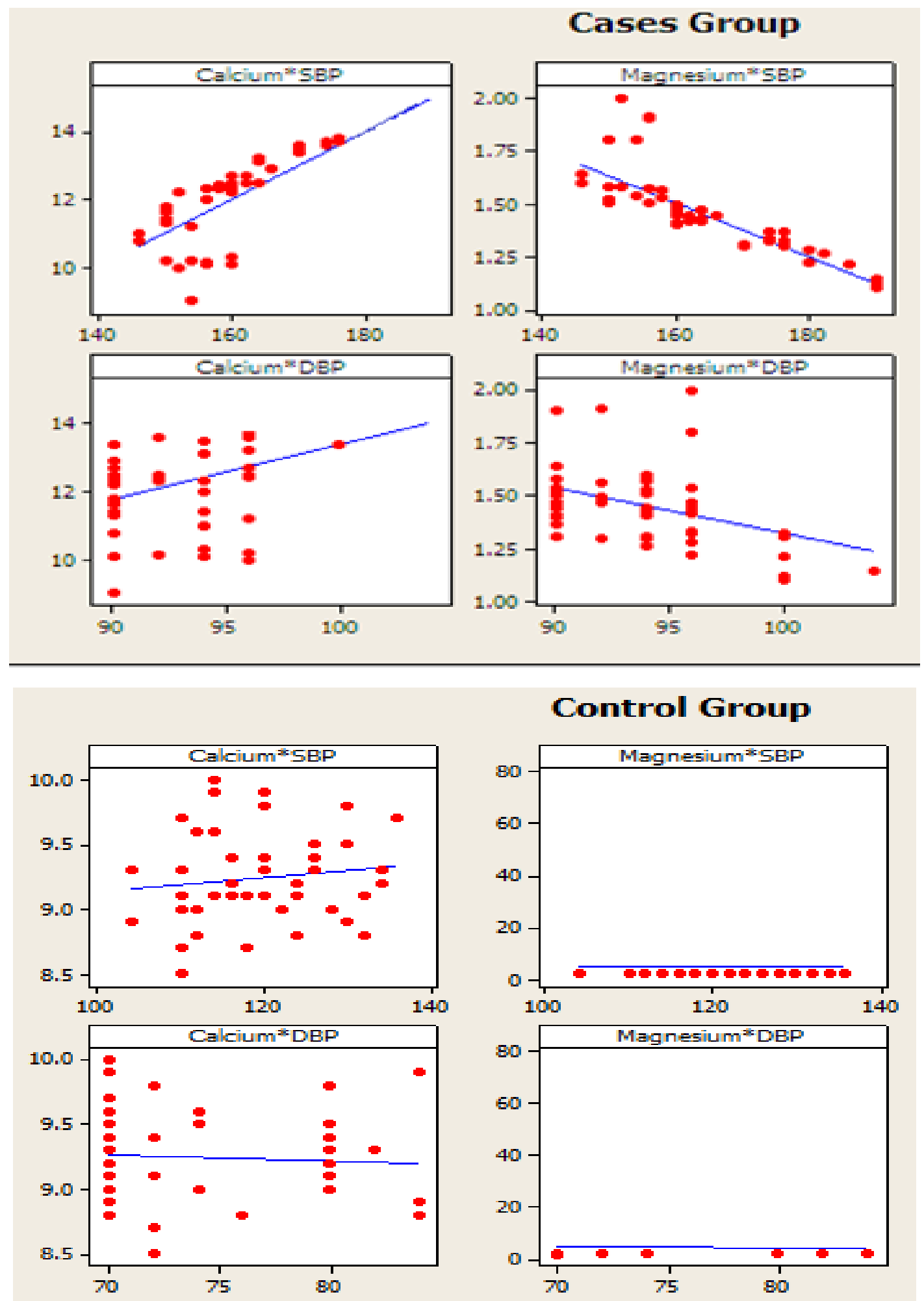

Fig 9: Scatter plot showing Pearson correlation of serum calcium and magnesium with SBP \& DBP in the study groups

The above table and figure, shows that there was a:

$>$ Significant positive correlation between serum calcium with,

SBP $\quad(\mathrm{r}=0.842, \quad \mathrm{p}$-value: $<0.001 * *)$ and DBP ( $\mathrm{r}=0.403$, p-value: $0.004 * *)$ in cases.
Significant negative correlation between serum magnesium with, SBP $(\mathrm{r}=-0.805, \mathrm{p}$-value: $<0.001 * *)$ and DBP ( $\mathrm{r}=-0.395$, $\mathrm{p}$-value:0.005**) in cases. 


\section{DISCUSSION}

Hypertension is one of the most common diseases affecting humans worldwide, due to the associated morbidity, mortality it is an important public healthcare challenge.[9]

HTN is like an iceberg disease but is a controllable disease, where a decrease in $\mathrm{BP}$ by $5 \mathrm{mmHg}$ can prevent $1,51,000$ strokes and 1,53,000 chronic heart disease death.[16]

Our study has been designed to evaluate and compare the serum levels of Calcium and Magnesium in essential hypertensive patients and normotensive healthy subjects.

The role of electrolytes in the pathophysiology of essential hypertension has been studied, factors determining the development and maintenance of arterial hypertension include vascular tone, contractility, reactivity and transmembrane potential, which are influenced by extracellular magnesium and calcium levels.[17]

In our study we obtained a significant $(\mathrm{p}<0.001 * *)$ increase in serum calcium level $12.38 \pm 1.42 \mathrm{mg} / \mathrm{dl}$ in cases as compared to controls, which is in agreement with the study of Wright et al.[18]

Study done by Resnick et al and Weidmann et al suggested that sudden elevation and depression of serum calcium level are followed by rising and falling of BP. $[19,20]$

An abnormal calcium metabolism may be a common denominator for abnormalities of cellular physiology associated with EHTN. [21,22]

Intracellular calcium ions are known to have direct effects on peripheral vascular tone. Data from animal models suggest further that with HTN smooth muscle is hyperresponsive to changes in extracellular calcium concentrations and that the vascular membrane permeability to calcium is increased.[22]

The other finding of our study was a significant $(\mathrm{p}<0.001 * *)$ decrease in serum magnesium level $1.46 \pm 0.19 \mathrm{mg} / \mathrm{dl}$ in cases as compared to controls.

Study done by Tammaro $\mathrm{P}$ et al found decreased concentrations of magnesium, potentiates vasoconstriction and increase vascular tone.[23]

Magnesium as a calcium channel blocker helps to reduce the release of calcium and thus reduces vascular resistance. Reduced extracellular magnesium activates calcium influx via calcium channels. Low intracellular magnesium concentrations stimulate inositol-tri-phosphate (IP3) mediated mobilization of intracellular calcium and reduce calcium-ATPase activity. Thus, calcium efflux and sarcoplasmic reticular calcium reuptake are reduced, leading to cytosolic accumulation of calcium and increased calcium concentration, which is a crucial factor for vasoconstriction.[24]

In our study, we found significant positive correlation between serum calcium with systolic blood pressure $\mathrm{r}=0.842$ $\left(\mathrm{p}<0.001^{* *}\right)$ and with diastolic blood pressure $\mathrm{r}=0.403 \quad(\mathrm{p}=0.004 * *)$; and $\mathrm{a}$ significant negative correlation between serum magnesium with systolic blood pressure $\mathrm{r}=-0.805(\mathrm{p}<0.001 * *)$ and with diastolic blood pressure $r=-0.395$ $\left(\mathrm{p}=0.005^{* *}\right)$ in essential hypertensive patients, which is in agreement with study done by Staessen et al. They also found that $\mathrm{Ca} 2+$ and $\mathrm{Mg} 2+$ are inversely correlated to each other in their effects on blood pressure.[25]

Study done by Kesteloot $\mathrm{H}$ et al and Robinson $\mathrm{D}$ et al reported a positive associations between BP levels and concentrations of serum total calcium.[26,27]

Study done by Resnick LM et al found an inverse association between magnesium intake and blood pressure level and also reported negative correlation between free magnesium with both systolic and diastolic blood pressure. [28]

Decreased serum magnesium is associated with increased cell membrane permeability, increased intracellular calcium 
and consequently increased vascular tone. [17]

\section{CONCLUSION}

In conclusion, the findings from our study, shows the imbalance in levels of serum calcium and magnesium among the patients of essential hypertension in comparison to controls.

These changes may play an important role in the pathogenesis of essential hypertension leading to endothelial dysfunction, ionic channel imbalance and oxidative stress.

This suggests that the impaired metabolism of these minerals may have a contributory role in the progression of essential hypertension and later development of complications.

Thus, Estimation of serum calcium and magnesium may be helpful in knowing the elemental involvement in the pathophysiology of essential hypertension and associated complications.

\section{Acknowledgement: None}

\section{Conflict of Interest: None}

\section{Source of Funding: None}

\section{Ethical Approval: Approved}

\section{REFERENCES}

1. Vanhoutte PM, Boulanger CM. Endothelium-dependent responses in hypertension: Hypertens Res. 1995; 18: 8798.

2. Carpenter WE, Toney G M, Lam D, Weintraub NL, Qin Z. Zinc, copper, and blood pressure: Human population studies. Medical Science monitor. 2013; 19: 1-8.

3. WHO The World Health Report: Reducing Risks, Promoting Healthy Life. Geneva: World Health Organization; 2002.

4. Chobanian AV, Barkis GL, Black HR, Cushman WC, Green LA, Izzo JL, et al. The Seventh Report of Joint National Committee on Prevention, Detection, Evaluation and Treatment of High Blood Pressure: the JNC report. JAMA. 2003; 289: 2560-72.
5. Beevers G, Lip GY, O'Brein E. ABC of hypertension: The pathophysiology of hypertension. BMJ. 2001; 322: 912-6.

6. Coy V. Genetics of essential hypertension. J Am Acad Nurse Pract. 2005; 17: 219-24.

7. Kotchen TA. Hypertensive vascular disease. Longo DL, Kasper DL, Jameson JL, Fauci AS, Hauser SL, Loscalzo J. Harrison's Principles of Internal MedicineHarrison. 18 Edition. Unites States of America: Mc Graw Hill Companies. 2012; Chapter 247: 20422059.

8. Coleman TG, Hall JE, Norman (Jr.). RA: Regulation of arterial blood pressure. In: Hypertension, 1st Edition (Eds BM Brenner and JH Stein), London: Churchill Livingstone Inc. 1981; 1-20.

9. Abbasi IR, Haque S, Kausar MW, Karira KA, Zubari NA. Correlation of divalent Cat Ions $\left(\mathrm{Ca}^{++}, \mathrm{Mg}^{++}\right)$and Serum Renin in patients of essential hypertension. J Pak Med Assoc. 2012; 62(2): 134-138.

10. Wright JT, Rahman M, Scarpa A, Fatholahi $M$, Griffin V, Jean-Baptiste $R$, et al. Determination of salt-sensitivity in blacks and whites Normotensive and Hypertensive women. Hypertension. 2003; 42: 1087-92.

11. Carretero OA, Oparil S. Essential hypertension. Part I: definition and etiology. Circulation. 2000 Jan; 101(3): 329-35.

12. Sontia B, Touyz RM. Role of magnesium in hypertension. Archives of Biochemistry and Biophysics. 2007; 458(1): 33-39.

13. Robert H Riffenburg. Statistics in Medicine, second edition, Academic press. 2005; 85125.

14. Sunder Rao $P$ S S, Richard J. An Introduction to Biostatistics, A manual for students in health sciences, New Delhi: Prentice hall of India. 4th edition. 2006; 86160.

15. Suresh KP, Chandrasekhar S. Sample Size estimation and Power analysis for Clinical research studies. Journal Human Reproduction Science. 2012; 5(1), 7-13.

16. Datla SR, Griendling KK. Hypertension Highlights Reactive Oxygen Species, NADPH Oxidases and Hypertension. Hypertension. 2010; 56: 325-330.

17. Touyz RM, Milne FJ, Seftel HC, Reinach SG. Magnesium, calcium, sodium and potasium status in normotensive and hypertensive Johannesburg residents. Samj. 1987 sept; 72(19). 
18. Wright JT, Rahman M, Scarpa A, Fatholahi M, Griffin V, Jean-Baptiste $\mathrm{R}$, et al. Determination of salt-sensitivity in blacks and whites Normotensive and Hypertensive women. Hypertension 2003; 42: 1087-92.

19. Resnick LM, Nicholsun JP, Laragh JH. Alteration in calcium metabolism mediate salt sensitivity in essential hypertension. Trans Assoc Ann Physian1985; 98: 313-21.

20. Weidmann P, Massry SG, Coburn WJ, Maxwell MH, Atleson J, Kleeman CR. Blood pressure effects of acute hypercalcemia. Studies in patients with chronic renal failure. Ann Intern Med.1972; 76: 741-5

21. Pawade YR, Ghangale SS, Apte IC, Nagdeote AN, Warade JP. Serum Calcium: Can It Be A Diagnostic And Prognostic Marker In Essential Hypertension? Journal of Clinical and Diagnostic Research. 2011 Feb; 5(1): 58-62.

22. Folsom AR, Smith CL, Prineas RJ, Grimm $\mathrm{RH}$, Jr. Serum Calcium Fractions in Essential Hypertensive and Matched Normotensive Subjects. Hypertension Journal of American Heart association. 1986; 8: 11-15.
23. Tammaro P, Smith AL, Crowley BL, Smirnov SV. Cardiovasc Res. 2005; 65 (2): 387-396.

24. Sontia B, Touyz RM. Role of magnesium in hypertension. Archives of Biochemistry and Biophysics. 2007; 458(1): 33-39.

25. Staessen JA, Wang J, Bianchi G, Birkenhager WH. Essential hypertension. Lancet 2003; 361: 1629-41.

26. Kesteloot H, Geboers J. Calcium and blood pressure. Lancet. 1982; 1: 813-815.

27. Robinson D, Bailey AR, Williams PT. Calcium and blood pressure. Lancet 1982; 2: 1215-1216.

28. Resnick LM, Gupta RK, Laragh JH. Intracellular free magnisum in erythrocytes of essential hypertension: relation to blood pressure and serum divalent captions. Proc Natt Acad Sci USA. 1984; 81: 6511-5.

How to cite this article: Asha G, Natikar JA, Mohanty $\mathrm{S}$ et al. Role of Divalent Cations in Pathophysiology of Essential Hypertension. Gal Int J Health Sci Res. 2021; 6(3): 7-15. DOI: https://doi.org/10.52403/gijhsr.20210702 